\title{
THE ESTIMATE OF THE DIFFERENCE OF INITIAL SUCCESSIVE COEFFICIENTS OF UNIVALENT FUNCTIONS
}

\author{
Zhigang Peng And Milutin Obradović
}

Abstract. Let $\mathscr{A}$ denote the family of all functions that are analytic in the unit disk $\mathbb{D}:=\{z$ : $|z|<1\}$ and satisfy $f(0)=0=f^{\prime}(0)-1$. Let $S$ be the set of all functions $f \in \mathscr{A}$ that are univalent in $\mathbb{D}$. In this paper the sharp upper bounds of $\left|a_{3}-a_{2}\right|$ and $\left|a_{4}-a_{3}\right|$ for the functions $f(z)=z+\sum_{n=2}^{\infty} a_{n} z^{n}$ being in several subclasses of $S$ are presented.

Mathematics subject classification (2010): 30C45.

Keywords and phrases: Univalent function, successive coefficient, upper bounds, estimate.

\section{REFERENCES}

[1] BRanges, L. D., A proof of the Bieberbach conjecture, Acta Mathematica, 1985, 154: 137-152.

[2] Duren, P. L., Univalent functions, New York: Springer-Verlag, 1983.

[3] Fournier, R., Ponnusamy, S., A class of locally univalent functions defined by a differential inequality, Complex Variables and Elliptic Equations, 2007, 52(1): 1-8.

[4] Hayman, W. K., On successive coefficients of univalent functions, J. London Math. Soc., 1963, 38: $228-243$.

[5] Kargar, R., Pascu N. R., Ebadian, A., Locally univalent approximations of analytic functions, J. Math. Anal. Appl., 2017, 453: 1005-1021.

[6] Leung, Y., Successive coefficients of starlike functions, Bull. London Math. Soc., 1978, 10: 193-196.

[7] Li, M., Sugawa, T., A Note on successive coefficients of convex functions, Computational Methods and Function Theory, 2017, 17: 179-193.

[8] LiberA, R. J., ZŁOTKIEWICZ, E. J., Early coefficients of the inverse of a regular convex function, Proc. Amer. Math. Soc., 1982, 85: 225-230.

[9] Marjono, Thomas, D. K., A Note on the Powers of Bazilevič Functions, International Journal of Mathematical Analysis, 2015, 9(42): 2061-2067.

[10] Obradović, M., Ponnus amy, S., Wirths, K. -J., Coefficient characterizations and sections for some univalent functions, Siberian Mathematical Journal, 2013, 54(4): 679-696.

[11] Obradović, M., Ponnusamy, S., Product of univalent functions, Mathematical and Computer Modelling, 2013, 57: 793-799.

[12] Obradović, M., Ponnusamy, S., Univalence and starlikeness of certain transforms defined by convolution, J. Math. Anal. Appl., 2007, 336: 758-767.

[13] Obradović, M., Ponnusamy, S., Radius of univalence of certain combination of univalent and analytic functions, Bulletin of the Malaysian Mathematical Sciences Society, 2012, 35(2): 325-334.

[14] Ohno, R., Sugawa, T., Coefficient estimates of analytic endomorphisms of the unit disk fixing a point with applications to concave functions, arXiv:1512.03148 [math.CV]

[15] Owa, S., Nunokawa, M., Saitoh H., Srivastava, H. M., Close-to-convexity, starlikeness, and convexity of certain analytic functions, Applied Mathematics Letters, 2002, 15: 63-69.

[16] Ozaki S., Nunokawa, M., The Schwarzian derivative and univalent functions, Proc. Amer. Math. Soc., 1972, 33: 392-394.

[17] Pommerenke, C., Probleme aus der Funktionentheorie, Jber Deutsch. Math. Verein., 1971, 73: 1-5.

[18] Robertson, M. S., Univalent functions starlike with respect to a boundary point, J. Math. Anal. Appl., 1981, 81: 327-345. 
[19] Singh R., Singh, S., Some sufficient conditions for univalence and starlikeness, Colloquium Mathematicum 1982, 47: 309-314.

[20] Singh, R., On Bazilevič functions, Proc. Amer. Math. Soc., 1973, 38: 261-271.

[21] YE, Z., On successive coefficients of odd univalent functions, Proc. Amer. Math. Soc., 2005, 133(11): 3355-3360.

[22] YE, Z., On the successive coefficients of close-to-convex functions, J. Math. Anal. Appl., 2003, 283: 689-695.

[23] YE, Z., The coefficients of Bazilevič functions, Complex Variables and Elliptic Equations, 2013, 58(11): 1559-1567.

[24] PEng, Z., ZHOng, G., Some properties for certain classes of univalent functions defined by differential inequalities, Acta Mathematica Scientia, 2017, 37B: 69-78. 